\title{
Academic Referencing - a dying art
}

\section{Graham Roberts $^{1}$}

Accepted: 16 March 2021 / Published online: 16 July 2021

(c) Springer Science+Business Media, LLC, part of Springer Nature 2021

The editorial on academic referencing [1] resonates strongly with my experience of over 40 years of supporting undergraduate and postgraduate scholars in their endeavors to conduct and report research.

It is with a strong voice that I echo Professor Byard's concerns.

Writing a paper suitable for a scientific journal is a unique skill and many young investigators find it difficult to reduce a master's or $\mathrm{PhD}$ thesis to a single paper. Time passes and the discipline to use appropriate and accurate references is often seen as a chore. It seems to be too much trouble and do the references matter that much anyway?

As a reviewer of innumerable submissions, I always look at the references - so often authors use the title of the paper to justify inclusion and do not properly check the content of the paper to ensure that the referential allusion is appropriate.

Drafting of the paper takes many hours of word processing just to reach the precise journal requirements. Reviewers assume, inappropriately, that this shortcoming is a reflection of the overall standard of the work. The quality of the work should be judged on the body of the paper not problems in the word processing of references. It is disheartening to have a paper rejected and this disappointment is heightened by the need to redraft the paper in the editorial format required.

A way forward with this issue is to use the 'Your Paper Your Way' approach of some publishing houses. This allows the research worker to make the submission, and the subsequent risk of rejection, without spending several hours on what is perceived as editorial minutiae. If the paper is accepted the investigator would be delighted to the point of delirium to carry out the editorial procedures required to make the paper publication ready. For the editor it would be a simple task to return an accepted paper as many times as is required to the author to bring up to standard the editorial requirements for publication.

Professor Byard is right, references are important and must be correctly quoted. But, save a thought for the young (or not so young) research worker who is putting considerable effort into career development and trying to publish their research work.

The employment of 'Your Paper Your Way' will ease the path for both parties.

\section{Reference}

1. Byard RW. Academic referencing - a dying art. Forensic Sci Med Pathol. 2021;17:1-2.

Publisher's Note Springer Nature remains neutral with regard to jurisdictional claims in published maps and institutional affiliations.
Graham Roberts

graham.roberts101@outlook.com

1 King's College London Dental Institute, London, UK 